\title{
STRATEGI PEMASARAN KOPI RARAK SEBAGAI DAERAH WISATA DI KABUPATEN SUMBAWA BARAT
}

\section{MARKETING STRATEGY OF RARAK COFFEE AS A TOURISM AREA IN WEST SUMBAWA REGENCY}

\author{
Eko Supriastuti ${ }^{1 *}$, Muhammad Nursan ${ }^{2}$ \\ ${ }^{1}$ Program Studi Agribisnis Universitas Cordova Fakultas Pertanian, Taliwang, Indonesia \\ ${ }^{2}$ Program Studi Agribisnis Fakultas Pertanian Universitas Mataram, Mataram, Indonesia \\ *Email Penulis korespondensi: eko.supriastuti82@gmail.com
}

\begin{abstract}
Abstrak
Kabupaten Sumbawa Barat memiliki daerah yang ketinggiannya mencapai 586 - $800 \mathrm{~m}$ di atas permukaan laut, yaitu Desa Rarak Ronges. Daerah ini sangat berpotensi dalam mengembangkan komoditi kopi. Selain penghasil kopi terbesar di Sumbawa Barat, Desa Rarak Ronges juga dijadikan sebagai desa wisata Namun hasil produksi dan pengolahan hasil produksi kopi masih kurang maksimal. Terutama pada pemasaran hasil olahan kopi rarak, belum bisa bersaing dengan kopi saset luar daerah. Sedangkang permintaan kopi di masyarakat cukup tinggi. Penelitian ini bertujuan untuk mengetahui untuk mengetahui strategi pemasaran Kopi Rarak sebagai daerah wisata di Kabupaten Sumbawa Barat. Metode yang digunakan dalam penelitian ini adalah metode penelitian deskriptif dengan metode analisis data yang digunakan adalah analisis SWOT. berdasarkan hasil penelitian didapatkan prioritas strategi pada tingkat pengusaha kopi yaitu 1) meningkatkan sdm dalam mengelolah penawaran lokasi wisata dan menu variasi sajian kopi dengan menyesuaikan selera konsumen, 2) meningkatkan dan memperbaiki sarana penunjang lokasi wisata agar menarik konsumen wisata guna meningkatkan pemasaran kopi, 3) meningkatkan kualitas dan kuantitas olahan racikan kopi dengan jangkauan pemasaran yang luas, dan 4) meningkatkan pemasaran tampilan racikan kopi dengan varian rasa yang modern untuk meningkatkan daya saing. kemudian strategi di tingkat pemerinntah yaitu 1) meningkatkan produksi dan menciptakan pasar baru dengan teknologi untuk meningkatkan kualitas dengan memaksimalkan dukungan pemerintah agar dapat bersaing dengan produk luar, dan 2). meningkatkan berbagai lokasi wisata yang strategis, fasilitas penginapan, akses jalan dan racikan kopi siap saji agar tercapai kepuasan dan kenyamanan pelanggan untuk meningkatkan jumlah konsumen.
\end{abstract}

Kata kunci: Kopi Rarak, Strategi Pengembangan, Pemasaran, Analisis SWOT

\begin{abstract}
West Sumbawa Regency has an area that reaches 586 - $800 \mathrm{~m}$ above sea level, namely Rarak Ronges Village. This area has the potential to develop coffee commodities. In addition to the largest coffee producer in West Sumbawa, Rarak Ronges Village is also used as a tourist village. However, the production and processing of coffee production is still not optimal. Especially in the marketing of processed Rarak coffee, it has not been able to compete with Saset coffee outside the region. Meanwhile, the demand for coffee in the community is quite high. This study aims to determine the marketing strategy of Rarak Coffee as a tourist area in West Sumbawa Regency. The method used in this research is descriptive research method with data analysis method used is SWOT analysis. Based on the results of the study, it was found that strategic priorities at the coffee entrepreneur level were 1) increasing human resources in managing the offer of tourist sites and menu variations of coffee offerings by adjusting consumer tastes, 2) improving and improving facilities supporting tourist sites in order to attract tourist consumers to increase coffee marketing, 3) improve the quality and quantity of processed coffee blends with a broad marketing reach, and 4) increase the marketing of the appearance of coffee blends with modern flavor variants to increase competitiveness. then the strategy at the government level is 1) increasing production and creating new markets with technology to improve quality by maximizing government support in order to compete with foreign products, and 2). improve various strategic tourist locations, lodging facilities, road access and ready-to-serve coffee blends in order to achieve customer satisfaction and convenience to increase the number of consumers.
\end{abstract}

Keywords: Rarak Coffee, Development Strategy, Marketing, SWOT Analysis

Supriastuti, E dan Nursan, M. 


\section{PENDAHULUAN}

Sektor pertanian masih merupakan sektor penting yang perlu dikembangkan dalam rangka mencapai pembangunan ekonomi di daerah (Nursan \& Septiadi, 2020). Kabupaten Sumbawa Barat merupakan salah satu daerah pengembangan pertanian di Provinsi Nusa Tenggara Barat dan memiliki beberapa daerah yang ketinggiannya mencapai 586 - 800 meter di atas permukaan laut yaitu salah satunya adalah Desa Rarak Ronges (BPS KSB, 2021). Potensi desa tersebut perlu dikelolah dan dimanfaatkan secara optimal terutama untuk memenuhi kebutuhan pangan komoditas pertanian dataran tinggi secara mandiri. Desa Rarak Ronges yang merupakan daerah dataran tinggi yang ada di Kabupaten Sumbawa Barat saat ini sudah mampu memproduksi tanaman perkebunan salah satunya yaitu kopi dan sampai saat ini daerah tersebut masih merupakan daerah penghasil Kopi Robusta. Dimana Kopi robusta dan Arabika masih merupakan jenis tanaman kopi Indonesia yang banyak diperdagangkan karena memiliki nilai ekonomi yang cukup tinggi (Rahardjo, 2012). Selain itu, Kopi Robusta juga merupakan jenis tanaman kopi yang memiliki areal penanaman dan produksi terbesar di Indonesia (Sari, Suhartati, \& Husniati, 2019).

Namun jika dilihat dari nilai produksi Kopi Robusta di Desa Rarak Ronges atau dikenal dengan Kopi Rarak masih relatif rendah karena sistem budidayanya masih tradisional dan pemasaran hasil olahan Kopi Rarak (bubuk) masih belum mampu bersaing dengan produk kopi dari luar daerah. Padahal aspek penting dalam agribisnis adalah pemasaran produk, jika pemasaran dapat berjalan dengan baik, maka akan memberikan keuntungan kepada semua pihak yang terlibat (Khaswarina, Kusumawaty, \& Eliza, 2019). Selain itu, pemasaran Kopi Robusta juga perlu dilakukan dengan menerapkan efisiensi dan efektivitas pada saluran pemasarannya, sehingga dapat meningkatkan keuntungan (Pratiwi, Kaskoyo, Herwanti, \& Qurniati, 2019). Pembentukan koperasi adalah salah satu cara untuk meningkatkan efisiensi pemasaran Kopi Robusta karena dapat meminimalisir lembaga pemasaran yang terlibat (Caesara, Baihaqi, \& Usman, 2017).

Selain sebagai daerah penghasil kopi, Desa Rarak Ronges juga dijadikan sebagai desa wisata karena memiliki fanorama yang indah, bukit yang dapat melihat pemandangan alam yang indah dibawahnya, suhu yang dingin, dan beberapa lokasi perkebunan yang dapat menarik wisatawan. Dengan dijadikannya Desa Rarak Ronges sebagai desa wisata maka dapat menjadi peluang yang besar dalam memasarkan olahan Kopi Rarak. Namun sampai saat ini hasil pemasaran olahan Kopi Rarak (bubuk) masih belum dilakukan secara maksimal. Hal ini karena kurangnya kemampuan dalam mengelolah strategi pemasaran kopi olahan yang harus mereka kembangkan sesuai dengan kondisi alam setempat. Oleh karena itu diperlukan suatu penelitian terkait dengan strategi pemasaran Kopi Rarak. Tujuan penelitian ini dilakukan adalah untuk mengetahui strategi pemasaran kopi Rarak sebagai daerah wisata di Kabupaten Sumbawa Barat.

\section{METODE PENELITIAN}

Penelitian ini dilaksanakan di Desa Rarak Ronges Kecamatan Brang Rea yang dipilih secara purposive sampling karena merupakan wilayah satu-satunya penghasil kopi di Kabupaten Sumbawa Barat. Penelitian ini dilakukan selama 3 (tiga) bulan dari Bulan September sampai dengan November 2021. Metode yang digunakan pada 
penelitian ini adalah metode penelitian deskriptif (Sugiyono, 2014). Data yang digunakan pada penelitian ini terdiri atas data kuantitatif dan data kualitatif yang berasal dari sumber primer dan skunder. Data primer merupakan data yang dikumpulkan dari hasil wawancara dengan nara sumber atau responden di lapangan seperti sumber/ahli, petani/kelompok tani, dan stakeholder pertanian baik pemerintah daerah maupun swasta yang dipilih secara purposive sampling. Sedangkan data skunder dikumpulkan dari beberapa instansi seperti Badan Sumbawa Barat dan instansi lainnya yang terkait. Data yang berhasil dikumpulkan kemudian dianalisis dengan menggunakan analisis SWOT. Analisis SWOT sering digunakan dalam menentukan strategi pengembangan baik pemasaran maupun usaha perusahaan (Rangkuti, 2015). Beberapa studi terkait penentuan strategi pengembangan di Kabupaten Sumbawa Barat dan daerah lainnya yang menggunakan analisis SWOT diantaranya penelitian Ariani \& Nursan (2017), Nursan \& Utama (2019), Nursan et al., (2020) dan Maryana et al., (2015).

\section{HASIL DAN PEMBAHASAN}

\section{Strategi Pemasaran Kopi Rarak Sebagai Daerah Wisata di Kabupaten Sumbawa Barat}

Kabupaten Sumbawa Barat terletak dibagian barat Pulau Sumbawa, yang memiliki luas wilayah sekitar $1.849,02 \mathrm{KM}^{2}$ terletak pada posisi $116,42^{0}-117,05^{0}$ Bujur Timur dan $08^{0} 29^{\prime}$ dan $9^{0} 07^{\prime}$ Lintang Selatan, dengan ketinggian 0-1.730 meter di atas permukaan laut. Wilayah dengan ketinggian ini sangat cocok untuk mengembangkan komoditi pertanian dataran tinggi terutama kopi dan agrowisatanya. Untuk mengetahui strategi yang digunakan dalam pengembangan pemasaran Kopi Rarak sebagai daerah wisata, terlebih dahulu mengidentifikasi faktor-faktor yang mempengaruhi pemasaran Kopi Rarak di Kabupaten Sumbawa Barat yang terdiri dari faktor lingkungan internal dan eksternal.

\section{Analisis Faktor Lingkungan Internal Pemasaran Kopi Rarak di Kabupaten Sumbawa Barat}

Analisis faktor lingkungan internal yang berpengaruh terhadap pemasaran Kopi Rarak di Kabupaten Sumbawa Barat terdiri dari faktor kekuatan dan kelemahan. Untuk lebih jelasnya dapat dilihat pada Tabel 1.

Tabel 1. Matrik Evaluasi Faktor Internal Kekuatan dan Kelemahan Pemasaran Kopi Rarak Sebagai Daerah Wisata di Kabupaten Sumbawa Barat Tahun 2021

\begin{tabular}{llrrr}
\hline & Uraian Faktor-Faktor Internal & Rating & Bobot & Skor \\
\hline A & Kekuatan (S) & & & \\
& \multirow{2}{*}{$\begin{array}{l}\text { Kualitas dan kuantitas kopi olahan } \\
\text { tinggi }\end{array}$} & 4,18 & 0,16 & 0,66 \\
& Jumlah produksi kopi petani tinggi & 3,91 & 0,15 & 0,58 \\
3 & Harga kopi tinggi & 4,09 & 0,16 & 0,63 \\
4 & Jumlah tenaga kerja & 3,71 & 0,14 & 0,52 \\
5 & Motivasi tenaga kerja & 3,73 & 0,14 & 0,53 \\
6 & Jumlah dan kualitas kopi yang & 3,62 & 0,14 & 0,50 \\
& dipasarkan & 3,15 & 0,12 & 0,37 \\
7 & Kelembagaan kelompok pariwisata & 26,38 & 1,00 & 3,80 \\
\hline
\end{tabular}




\begin{tabular}{lllll}
\hline B & Kelemahan (W) & & \\
1 & Jumlah wisawan rendah & 3,63 & 0,18 & 0,65 \\
2 & Variasi rasa rendah & 3,25 & 0,16 & 0,53 \\
3 & Waktu dan cara pemasaran kopi kering & 3,50 & 0,17 & 0,61 \\
4 & Keterampilan tenaga kerja & 3,13 & 0,16 & 0,49 \\
5 & Pemasaran kopi olahan (bubuk) rendah & 3,38 & 0,17 & 0,57 \\
6 & Kurangnya kerjasama toko renakan & 3,23 & 0,16 & 0,52 \\
& $\quad$ (pemasar) & 20,11 & 1,00 & 3,36 \\
& Total B & & & 0.44 \\
\hline
\end{tabular}

Sumber: Data primer, diolah (2021)

Faktor yang paling dominan sebagai faktor kekuatan yaitu kualitas dan kuantitas Kopi Rarak tinggi dengan skor (0.66). Berdasarkan data BPS Kabupaten Sumbawa Barat tahun 2020 produksi kopi di Desa Rarak sebanyak 149,5 ton dengan luas areal penanaman sebesar 250 hektar (BPS KSB, 2021). Hal ini juga sesuai dengan hasil lapangan bahwa berapapun jumlah produksi yang dihasilkan petani, pembeli tetap membeli kopi dengan harga yang stabil. Harga perkilo kopi kering saat ini mencapai Rp. 28.000 - Rp. 30.000 per kilo. Selain faktor kekuatan pemasaran kopi juga memiliki kelemahan tertinggi yaitu jumlah wisatawan yang rendah yaitu $(0,65)$.

Secara keseluruhan hasil analisis faktor lingkungan internal pemasaran Kopi Rarak di Kabupaten Sumbawa Barat masih didominasi oleh faktor kekuatan dibandingkan dengan faktor kelemahan yaitu dengan selisih sebesar 0.44. Ini berarti bahwa dalam menerapkan stategi pemsaran Kopi Rarak perlu dilakukan dengan mengotimalkan kekuatan untuk meminimalisir kelemahan yang dimiliki. Hasil ini sejalan dengan penelitian Maryana et al., (2015), Ariani \& Nursan (2017), dan Nursan et al., (2020) yang menemukan bahwa nilai faktor kekuatan masih dominan dibandingkan dengan faktor kelemahan.

\section{Analisis Faktor Lingkungan Eksternal Pemasaran Kopi Rarak Sebagai Desa Wisata di Kabupaten Sumbawa Barat}

Analisis faktor lingkungan eksternal terdiri dari atas peluang dan ancaman. Secara rinci terkait peluang dan ancaman pengembangan pemasaran Kopi Rarak di Kabupaten Sumbawa Barat dapat dilihat pada Tabel 2.

Tabel 2. Matrik Evaluasi Faktor Eksternal Peluang dan Ancaman Pemasaran Kopi Rarak Sebagai Desa Wisata di Kabupaten Sumbawa Barat 2021

\begin{tabular}{|c|c|c|c|c|}
\hline \multirow{2}{*}{$\mathrm{A}$} & Uraian Faktor-Faktor Eksternal & Rating & Bobot & Skor \\
\hline & Peluang (O) & & & \\
\hline 1 & Pencinta kopi tinggi & 4,18 & 0,16 & 0,66 \\
\hline 2 & Banyak lokasi wisata yang strategis & 3,61 & 0,14 & 0,51 \\
\hline 3 & Kebijakan akses jalan wisata & 4,09 & 0,16 & 0,65 \\
\hline 4 & Tingkatkan desain wisata & 3,01 & 0,12 & 0,35 \\
\hline 5 & Tingkatkan fasilitas penginapan & 3,73 & 0,15 & 0,54 \\
\hline 6 & Tingkatkan kepuasan dan kenyamanan & 3,52 & 0,14 & 0,48 \\
\hline 7 & $\begin{array}{l}\text { Wisatawan banyak, pemasaran } \\
\text { meningkat }\end{array}$ & 3,55 & 0,14 & 0,49 \\
\hline
\end{tabular}




\begin{tabular}{lllll}
\hline & Total A & 25,69 & 1,00 & 3,69 \\
& & Ancaman (T) & & \\
1 & Selera konsumen yang berubah-ubah & 3,25 & 0,19 & 0,61 \\
2 & Stan pemasaran tidak berkembang & 3,83 & 0,22 & 0,84 \\
3 & Minimnya menu komplementer & 3,71 & 0,21 & 0,79 \\
4 & Jaminan keamanan wisatawan & 3,23 & 0,19 & 0,60 \\
5 & Pesaing produk luar & 3,38 & 0,19 & 0,66 \\
& Total B & 17,4 & 1 & 3,50 \\
& Selisih & & & 0,19 \\
\hline
\end{tabular}

Sumber: Data primer, diolah (2021)

Faktor peluang yang paling dominan adalah pencinta kopi yang meningkaat dengan nilai 0.66. saat ini meningkatnya konsumsi kopi dikarenakan oleh semakin bertambahnya masyarakat pencita kopi dan ditunjang juga oleh usaha pemerintah di bidang perkebunan untuk meningkatkan pendapatan petani Indonesia. Akan tetapi daya beli kopi masyarakat Kabupaten Sumbawa Barat tidak terlalu tinggi. Maka dari itu petani sebagian besar menjual hasil kopinya ke luar daerah seperti Sumbawa Besar, dan sebagian dibeli oleh pengusaha yang datang ke lokasi dan dipasarkan keluar daerah. Hanya sebagian kecil yang di kelolah oleh masyarakat menjadi kopi olahan (kopi bubuk). Sehingga harga kopi dari tahun 2018 sampai tahun 2021 mengalami peningkatan yang cukup tinggi yaitu dari Rp.23.000 menjadi Rp. 28.000 per kilo gram.

Ancaman terbesar dalam pemasaran kopi rarak sebagai desa wisata adalah Stan pemasaran rendah dengan skor (0.71). Masyarakat Desa Rarak dalam pengembangan kopi masih secara tradisional. Pemerintah dalam hal ini tetap melakukan upaya di antaranya $m$ pelatihan diataranya cara cara pengolahan kopi, yaitu dengan memberikan bantuan peralatan sortir dan penggilingan kopi. Walaupun bantuan yang diberikan pemerintah masih minim jumlahnya sehingga pendapatan pengusaha pengelolah kopi bubuk belum dapat meningkatkan pendapatnya, maka dari itu pengrajin kopi bubuk harus mengetahui atau memahami strategi yang harus digunakan dalam pemasan kopi rarak sebagai desa wisata. Secara keseluruhan hasil analisis faktor lingkungan internal pemasaran Kopi Rarak di Kabupaten Sumbawa Barat masih didominasi oleh faktor peluang dibandingkan dengan faktor ancaman dengan nilai selisih sebesar 0.19. Ini berarti bahwa dalam menerapkan stategi pemsaran Kopi Rarak perlu dilakukan dengan memanfaatkan peluang yang dimiliki untuk menghindari ancaman. Hal ini sejalan dengan temuan pada penelitian Ariani \& Nursan, (2017), dan Nursan et al., (2020) yang menyatakan bahawa faktor peluang masih dominan dibandingkan dengan faktor ancaman. Kemudian untuk merumuskan strategi pengembangan Pemasaran Kopi Rarak sebagai daerah wisata di Kabupaten Sumbawa Barat, harus dibuat matrix space. Lebih jelasnya bisa dilihat pada Gambar 1 berikut ini. 


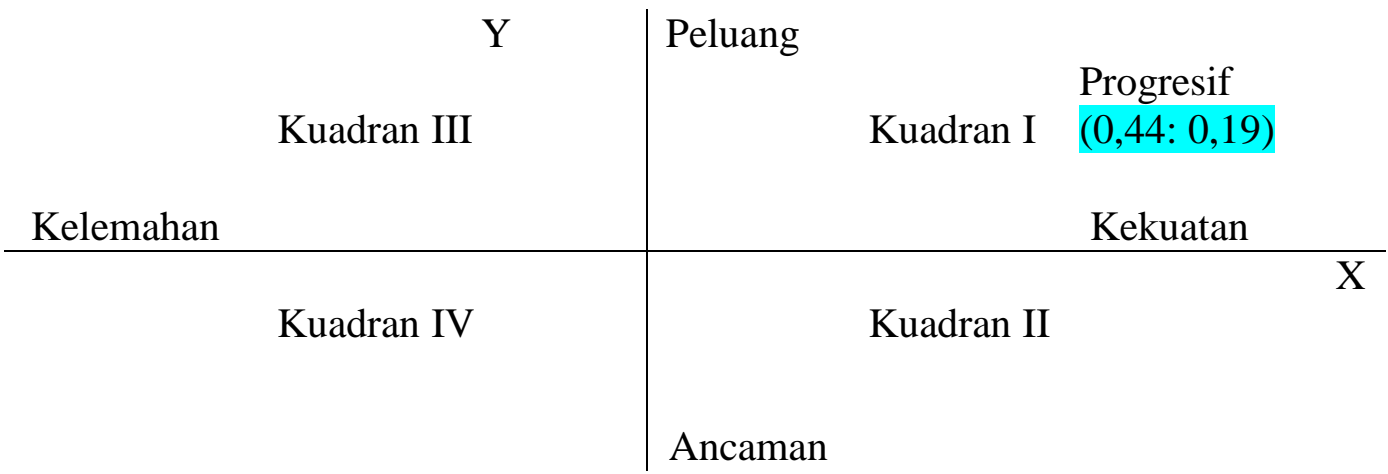

\section{Gambar 1. Matrix Space}

Dari hasil analisis faktor lingkungan internal dan eksternal yang didapat dari selisih antara total skor kekuatan dan total skor kelemahan menjadi sumbu (x), dan selisih total skor peluang dan total skor ancaman menjadi sumbu (y) pada kuadran SWOT. Berdasarkan analisis matrix space kuadran SWOT posisi faktor internal dan eksternal pengembangan pemasaran kopi saat ini berada pada kuadran $\mathrm{I}(+,+)$. Posisi ini menandakan sebuah pengembangan pemasaran Kopi Rarak yang kuat dan berpeluang, rekomendasi strategi yang diberikan adalah Progresif, artinya pemasaran dalam kondisi prima dan mantap sehingga sangat dimungkinkan untuk terus pemasaran kopi rarak sebagai kopi olahan yang beragam rasa. Strategi progresif ini juga diterapkan pada beberapa penelitian sebelumnya seperti pada penelitian Ariani \& Nursan, (2017) dan Nursan et al., (2020).

Tabel 3. Matrik SWOT Pemasaran Kopi Rarak Sebagai Desa Wisata

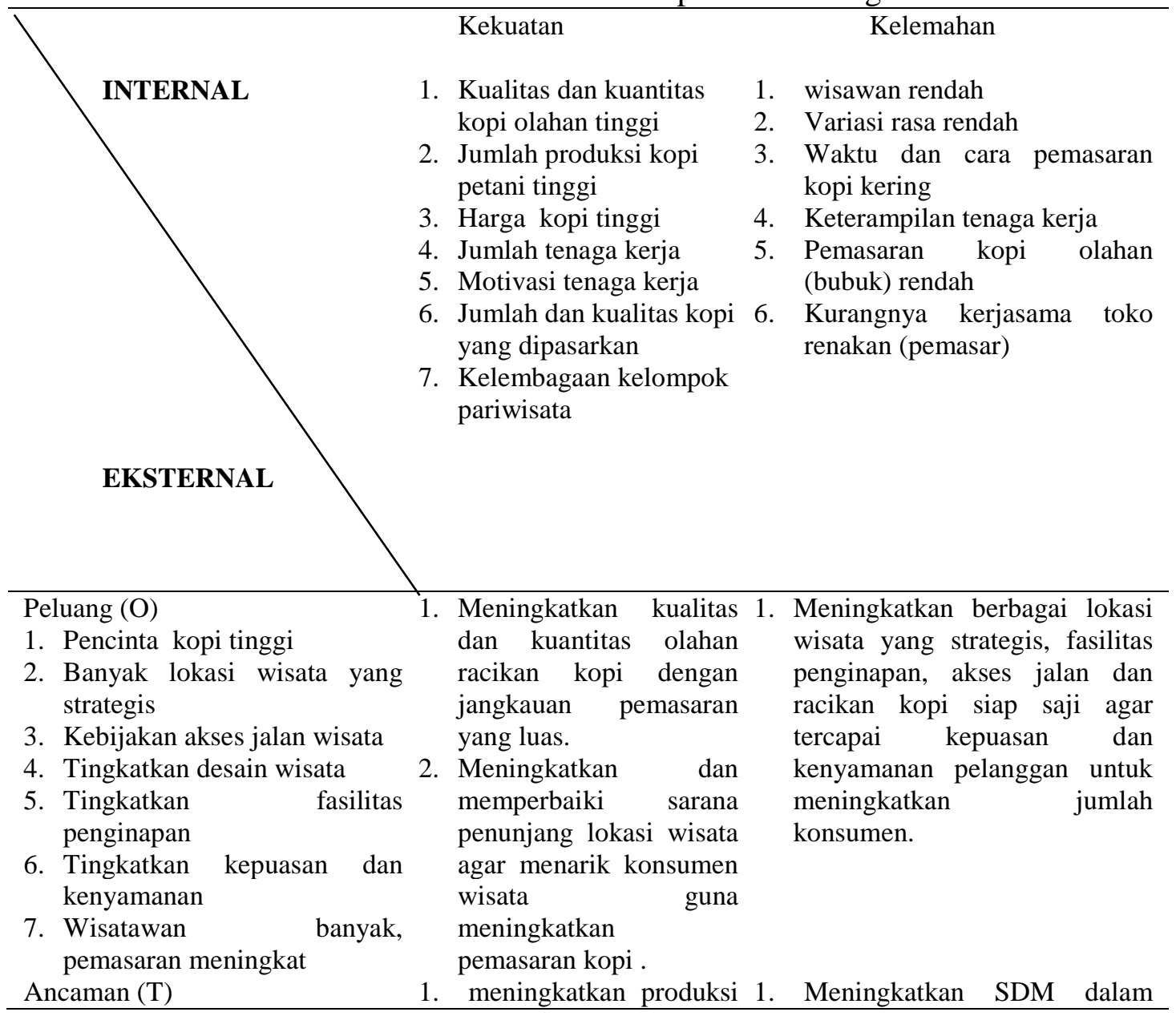


1. Selera konsumen yang dan menciptakan pasar berubah-ubah

2. Stan pemasaran tidak berkembang

3. Minimnya komplementer

4. Jaminan keamanan wisatawan

5. Pesaing produk luar baru dengan teknologi untuk meningkatkan memaksimalkan dukungan pemerintah. agar dapat bersaing dengan produk luar. kualitas dengan mengelolah penawaran lokasi wisata dan menu variasi sajian kopi dengan menyesuaikan selera konsumen.

2. Meningkatkan pemasaran tampilan racikan kopi dengan varian rasa yang modern tuk meningkatkan daya saing.

Dari hasil Analisis SWOT diatas strategi yang didapat harus dilakukan secara berkesinambungan (keterkaitan) antara pemerintah dengan masyarakat pelaku usaha. Karena strategi ini harus berjalan serentak tentunya memerlukan biaya atau pendanaan yang tidak sedikit maka strategi kebijakan disusun berdasarkan prioritas untuk dapat digunakan sebagai pedoman atau dasar dalam setiap tahap pembuatan kebijakan oleh pemerintah. Maka dari itu di strategi dibagi menjadi dua tingkatan yaitu (1) Strategi pengembangan pada tingkat pengusaha (2) strategi kebijakan pengembangan pada tingkat pemerintah.

\section{Strategi Kebijakan Pemasaran Kopi Rarak Sebagai Daerah Wisata di Kabupaten Sumbawa Barat pada Tingkat Pengusaha}

Strategi yang harus di pertimbangkan oleh pengusaha untuk mengembangkan pemasaran Kopi Rarak Sebagai Daerah Wisata di Kabupaten Sumbawa Barat terdiri dari 4 prioritas strategi, beserta skor prioritasnya yaitu:

Tabel 4. Prioritas Strategi pada Tingkat pengusaha untuk mengembangkan pemasaran kopi rarak di Kabupaten Sumbawa Barat 2021.

\begin{tabular}{ll}
\hline No & \multicolumn{1}{c}{ Prioritas Strategi } \\
\hline 1 & $\begin{array}{l}\text { Meningkatkan kualitas dan kuantitas olahan racikan kopi dengan } \\
\text { jangkauan pemasaran yang luas. }\end{array}$ \\
2 & $\begin{array}{l}\text { Meningkatkan dan memperbaiki sarana penunjang lokasi wisata agar } \\
\text { menarik konsumen wisata guna meningkatkan pemasaran kopi . }\end{array}$ \\
3 & $\begin{array}{l}\text { Meningkatkan SDM dalam mengelolah penawaran lokasi wisata dan menu } \\
\text { variasi sajian kopi dengan menyesuaikan selera konsumen. }\end{array}$ \\
4 & $\begin{array}{l}\text { Meningkatkan keterampilan tampilan racikan kopi dengan varian rasa yang } \\
\text { modern tuk meningkatkan daya saing. }\end{array}$ \\
\hline
\end{tabular}

\section{Strategi Kebijakan Pemasaran Kopi Rarak Sebagai Daerah Wisata di Kabupaten Sumbawa Barat pada Tingkat Pemerintah}

Strategi yang harus dipertmbangkan oleh pemerintah untuk mengembangkan pemasaran Kopi Rarak Sebagai Daerah Wisata di Kabupaten Sumbawa Barat dapat dilihat pada tabel berikut:

Tabel 5. Prioritas Strategi Pemasaran Kopi Rarak Sebagai Desa Wisata di Kabupaten Sumbawa Barat 2021

\begin{tabular}{ll}
\hline No & \multicolumn{1}{c}{ Prioritas Strategi } \\
\hline 1 & $\begin{array}{l}\text { Meningkatkan produksi dan menciptakan pasar baru dengan teknologi } \\
\text { untuk meningkatkan kualitas dengan memaksimalkan dukungan pemerintah }\end{array}$ \\
& $\begin{array}{l}\text { agar dapat bersaing dengan produk luar. } \\
\text { Meningkatkan berbagai lokasi wisata yang strategis, fasilitas penginapan, } \\
\text { akses jalan dan racikan kopi siap saji agar tercapai kepuasan dan } \\
\text { kenyamanan pelanggan untuk meningkatkan jumlah konsumen. }\end{array}$ \\
\hline
\end{tabular}




\section{KESIMPULAN DAN SARAN}

Dari hasil penelitian yang peneliti lakukan, maka dapat diambil kesimpulan bahwa strategi pemasaran Kopi Rarak sebagai desa wisata di Kabupaten Sumbawa Barat dibagi menjadi dua yaitu:

1. Strategi pada tingkat pengusaha kopi yaitu 1). Meningkatkan SDM dalam mengelolah penawaran lokasi wisata dan menu variasi sajian kopi dengan menyesuaikan selera konsumen. 2). Meningkatkan dan memperbaiki sarana penunjang lokasi wisata agar menarik konsumen wisata guna meningkatkan pemasaran kopi. 3). Meningkatkan kualitas dan kuantitas olahan racikan kopi dengan jangkauan pemasaran yang luas. 4). Meningkatkan pemasaran tampilan racikan kopi dengan varian rasa yang modern untuk meningkatkan daya saing.

2. Strategi di tingkat pemerinntah yaitu 1). Meningkatkan produksi dan menciptakan pasar baru dengan teknologi untuk meningkatkan kualitas dengan memaksimalkan dukungan pemerintah agar dapat bersaing dengan produk luar. 2). Meningkatkan berbagai lokasi wisata yang strategis, fasilitas penginapan, akses jalan dan racikan kopi siap saji agar tercapai kepuasan dan kenyamanan pelanggan untuk meningkatkan jumlah konsumen.

\section{DAFTAR PUSTAKA}

Ariani, Z., \& Nursan, M. (2017). Strategi Pengembangan Desa Mantar Sebagai Kawasan Desa Wisata di Kabupaten Sumbawa Barat. Biologi Tropis, 17(2), 58-68.

BPS KSB. (2021). Kabupaten Sumbawa Barat Dalam Angka Tahun 2021. Kabupaten Sumbawa Barat: Badan Pusat Statistik Kabupaten Sumbawa Barat.

Caesara, V., Baihaqi, A., \& Usman, M. (2017). Analisis pendapatan dan efisiensi pemasaran biji kopi (green bean) arabika di Kabupaten Bener Meriah. Jurnal Ilmiah Mahasiswa Pertanian Unsyiah, 2(1), 250-261.

Khaswarina, S., Kusumawaty, Y., \& Eliza. (2019). Analisis Saluran Pemasaran dan Marjin Pemasaran Bahan Olahan Karet Rakyat (Bokar) di Kabupaten Kampar. Unri Conference Series: Agriculture and Food Security, 88-97. Universitas Riau. https://doi.org/https://doi.org/10.31258/unricsagr.1a12

Maryana, I. K., Ustriyana, I. N. G., \& Parining, N. (2015). Strategi Pemasaran Kopi Bubuk Lumbung Mas Kelurahan Beng Kecamatan Gianyar Kabupaten Gianyar. Jurnal Agribisnis Dan Agrowisata, 4(3), 175-184.

Nursan, M., Nabilah, S., \& Sari, N. M. W. (2020). Potensi dan Strategi Pengembangan Kawasan Minapolitan Kertasari Kabupaten Sumbawa Barat. Jurnal Ilmiah Membangun Desa Dan Pertanian (JIMDP), 5(6), 192-201.

Nursan, M., \& Septiadi, D. (2020). Penentuan Prioritas Komoditas Unggulan Peternakan di Kabupaten Sumbawa Barat. Jurnal Agribisnis Dan Ilmu Sosial Ekonomi Pertanian, 5(1), 29-34.

Nursan, M., \& Utama, F. A. (2019). Strategi Pengembangan Badan Usaha Milik Desa (Bumdes) Berbasis Pertanian Di Kabupaten Sumbawa Barat. 8(2), 67-78. https://doi.org/http://dx.doi.org/10.26418/j.sea.v8i2.37726

Pratiwi, A. M., Kaskoyo, H., Herwanti, S., \& Qurniati, R. (2019). Saluran Pemasaran Kopi Robusta (Coffea Robusta) Di Agroforestri Pekon Air Kubang, Kecamatan Air Naningan, Kabupaten Tanggamus. Jurnal Belantara, 2(2), 76-83. 
Rahardjo, P. (2012). Kopi. Depok: Penebar Swadaya.

Rangkuti, F. (2015). Analisis SWOT. Jakarta: PT Gramedia Pustaka Utama.

Sari, M. Y., Suhartati, T., \& Husniati. (2019). Analisis Senyawa Asam Klorogenat Dalam Biji Kopi Robusta (Coffea canephora) Menggunakan HPLC. Analit: Analytical and Environmental Chemistry, 4(2), 86-93. https://doi.org/http://dx.doi.org/10.23960/aec.v4.i2.2019.p86-93

Sugiyono. (2014). Metode Penelitian Kuantitatif Kualitatif dan R\&D. Bandung: Alfabeta. 